\title{
How I manage ICP-CPP: a visual, yet individualized approach
}

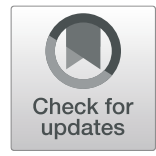

\author{
William D. Freeman ${ }^{1,2,3}$ (B) \\ This comment refers to the article available at https://doi.org/10.1186/s13054-019-2529-z.
}

I read with great interest Drs. Robba and Citerio's [1] approach to intracranial pressure (ICP)-cerebral perfusion pressure (CPP) management, and it is to be commended. My approach over the years has evolved to teach a visual pyramidal approach to our nurses, residents, fellows, and now our advanced practice providers and neurosurgeons. Rather than use the Tier 0, 1, 2, 3 system as proposed by the Neurocritical Care Society in Emergency Neurologic Life Support, I often simply provide this Fig. 1 to our teams to show the foundation is laid with basics of CPP (mean arterial pressure-ICP) management. This visual diagram shows that to measure CPP, an ICP monitor and basic interventions like head/ neck positioning are needed. The diagram also demonstrates the importance of emphasizing the ICP-CPP zero at the tragus for standardization $[2,3]$. These fundamentals cannot be overstated, especially with nurses eager to re-emphasize at bedside the goals of care of the patient. Further, beyond basic CPP management, osmotherapy comes into play, which once exhausted, moves up the pyramid to escalation therapies of refractory ICP, including barbiturates or hypothermia, and ultimately to neurosurgical decompression ("top of the pyramid" literally and figuratively). We find this Fig. 1 useful for discussion, and even management with our fellows, as well as for long-standing issues about use of mannitol versus say hypertonic saline in osmotherapy selection, etc. We find that there is an insatiable academic thirst for knowledge around this topic each year among all team members and hope this Fig. 1 provides food for thought for similar teams at other centers [4].

\author{
Acknowledgements \\ None. \\ Author's contributions \\ WDF is the sole contributor to this work, and so, contributed to every aspect. \\ The author read and approved the final manuscript. \\ Funding \\ None. \\ Availability of data and materials \\ NA. \\ Ethics approval and consent to participate \\ NA. \\ Consent for publication \\ NA. \\ Competing interests \\ The author declares that he has no competing interests. \\ Author details \\ 'Department of Neurology, Mayo Clinic, 4500 San Pablo Rd, Jacksonville, FL \\ 32224, USA. ²Department of Neurosurgery, Mayo Clinic, Jacksonville, FL, USA. \\ ${ }^{3}$ Department of Critical Care Medicine, Mayo Clinic, Jacksonville, FL, USA. \\ Received: 25 July 2019 Accepted: 13 August 2019 \\ Published online: 27 August 2019 \\ References \\ 1. Robba C, Citerio G. How I manage intracranial hypertension. Crit Care. 2019; \\ 23:243. \\ 2. Freeman WD. Management of Intracranial Pressure. Continuum (Minneap \\ Minn). 2015;21:1299-323. \\ 3. Freeman WD. Cerebral perfusion pressure versus intracranial pressure-driven \\ therapy on outcomes. Crit Care Med. 2015;43:e29. \\ 4. Lewandowski-Belfer JJ, Patel AV, Darracott RM, Jackson DA, Nordeen JD, \\ Freeman WD. Safety and efficacy of repeated doses of 14.6 or $23.4 \%$ \\ hypertonic saline for refractory intracranial hypertension. Neurocrit Care. \\ 2014;20:436-42.
}

\section{Publisher's Note}

Springer Nature remains neutral with regard to jurisdictional claims in published maps and institutional affiliations.

Correspondence: freeman.william1@mayo.edu

${ }^{1}$ Department of Neurology, Mayo Clinic, 4500 San Pablo Rd, Jacksonville, FL 32224, USA

2Department of Neurosurgery, Mayo Clinic, Jacksonville, FL, USA

Full list of author information is available at the end of the article

(c) The Author(s). 2019 Open Access This article is distributed under the terms of the Creative Commons Attribution 4.0 International License (http://creativecommons.org/licenses/by/4.0/), which permits unrestricted use, distribution, and reproduction in any medium, provided you give appropriate credit to the original author(s) and the source, provide a link to the Creative Commons license, and indicate if changes were made. The Creative Commons Public Domain Dedication waiver (http://creativecommons.org/publicdomain/zero/1.0/) applies to the data made available in this article, unless otherwise stated. 


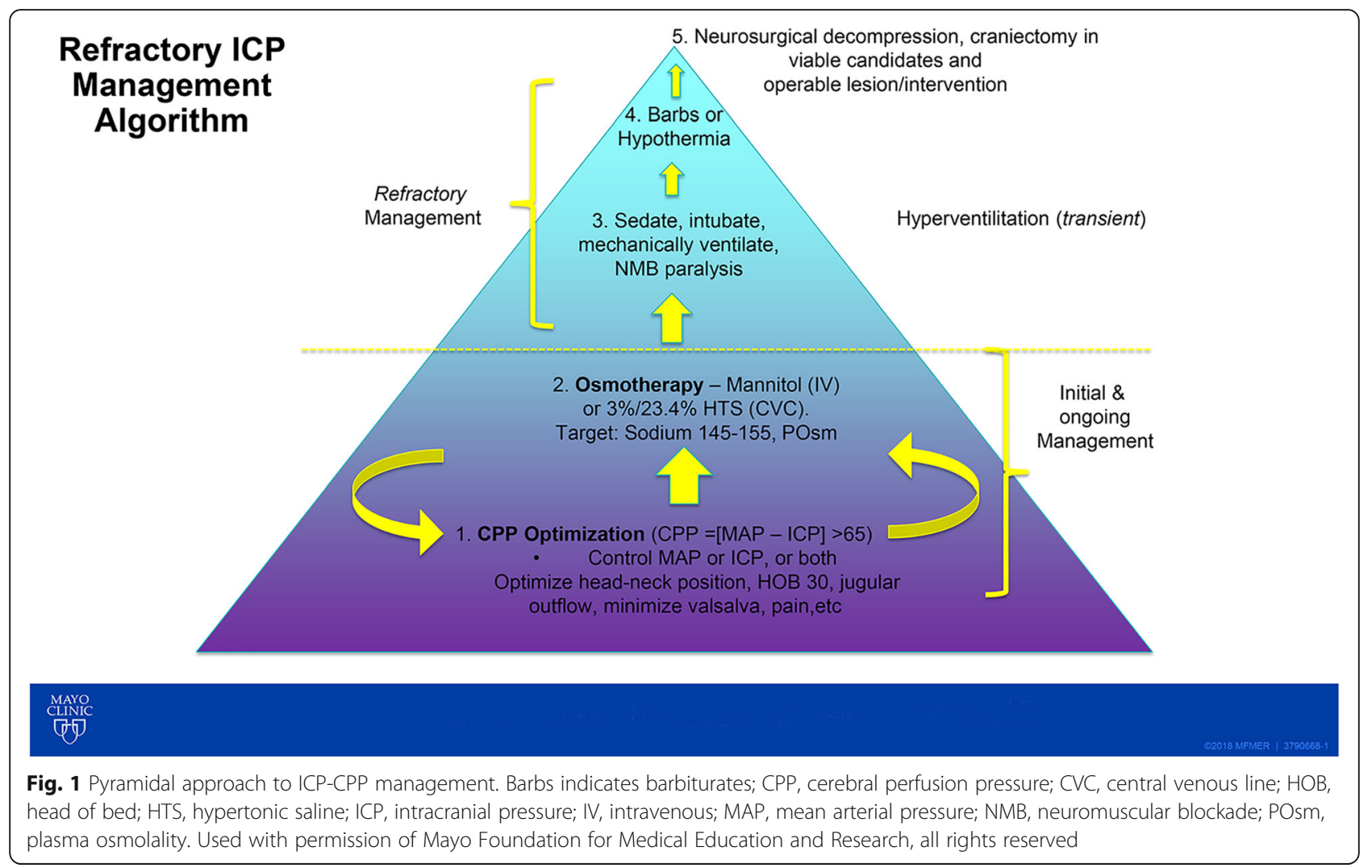

